\title{
A Position Paper of the American Academy of Neurology Ethics and Humanities Subcommittee
}

Neurologists often encounter ethical issues in the management of patients with cerebrovascular diseases. Previous American Academy of Neurology (AAN) position papers have discussed several of these issues and itemized the resulting ethical duties of neurologists: 1) to abide by the treatment consent or refusal of competent patients and the authorized proxy decision makers of incompetent patients ${ }^{1,2} ; 2$ ) to respect the right of patients to refuse lifesustaining therapy even if they may die as a result ${ }^{3,4}$; 3 ) to enhance the psychological and communicative abilities of disabled patients to better enable them to maximally participate in decisions about their treatment $^{1}$; 4) to follow the terms of legally authorized advance directives for medical care ${ }^{3-5}$; and 5) to provide optimal palliative care to dying patients. ${ }^{5,6}$ This position paper supplements the previously published ones by focusing on consent issues that may arise in the management of patients with cerebrovascular diseases. It applies equally to consent issues in the management of patients with other conditions.

Elements of valid consent. The doctrine of informed (or valid) consent forms the cornerstone of the patient-physician relationship. Except in emergency circumstances (in which the doctrine of presumed consent is operational), physicians must first obtain valid consent from the patient or authorized proxy decision maker before embarking on a course of diagnostic tests or treatments.

Consent is a process and not an event. It is a dialogue and information exchange between the patient and physician leading to permission for the physician to initiate tests or treatments. The signature on a consent form is not itself the consent; it is only the formalization of a preceding consent dialogue between the patient and physician.

The term "valid consent" is preferable to the more commonly used term "informed consent" because it emphasizes that the physician's presentation of information alone is insufficient for an ethically valid consent. Three elements of consent are necessary and sufficient for a patient's consent to become valid. First, the patient must have adequate decisionmaking capacity to provide consent. This element requires that the patient can comprehend relevant information presented about his or her condition, can process the information, and can express a decision. Second, the physician must present adequate information to the patient. Adequate information is that which a reasonable patient would need to know to make an informed decision. Adequate information includes the choice of options, a general understanding of the risks and benefits of each option, and a recommendation by the physician including reasons for the recommendation. Third, the patient's decision must be made freely, without coercion by the physician, family, or any agency. ${ }^{7}$

Consent for diagnostic testing. A common example of obtaining valid consent in the context of cerebrovascular disease is obtaining permission to perform carotid arteriography to investigate critical internal carotid stenosis. Because carotid arteriography usually is a prerequisite for carotid endarterectomy (which may be the treatment of choice in many circumstances of symptomatic critical carotid stenosis), physicians must obtain a patient's consent for carotid arteriography when the procedure is recommended. To satisfy the adequate-information component of valid consent, the patient must be told the

\footnotetext{
*See the Appendix on page 11 for a list of members of the American Academy of Neurology Ethics and Humanities Subcommittee.

From the American Academy of Neurology, St. Paul, MN.

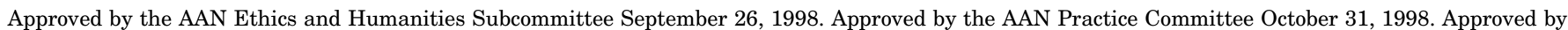
the AAN Board of Directors February 27, 1999. 
nature, risks, and benefits of both the arteriography/ endarterectomy treatment option and the nonsurgical/antiplatelet drug treatment option, and why the neurologist recommends the former. Accurate local data on morbidity and mortality with both options are essential components of this information. If the patient lacks the capacity to comprehend and process this information, a proxy decision maker should be identified to provide consent on the patient's behalf. Neurologists should not employ threats, coercion, or exaggerations of fact to gain consent.

If the patient or proxy refuses to consent to the procedure, the neurologist is permitted try to convince them that the patient is making a mistake. This argument can restate the facts and emphasize why the recommended treatment is superior to the alternative. However, if the patient continues to refuse, the neurologist should respect that the patient has the right to refuse and accept the decision. There are few, if any, circumstances in which the neurologist is morally justified to overrule the patient's valid refusal of testing and order arteriography over the patient's objection. ${ }^{7}$

Consent for therapy. Two relatively common contemporary treatments for cerebrovascular disease require carefully obtained valid consent: IV tissue plasminogen activator (tPA) and carotid endarterectomy. Long-term benefits for both treatments have been shown in controlled studies: improvement in functional outcome at 6 months in selected patients in whom IV tPA had been administered within 3 hours of the first symptom of an ischemic stroke ${ }^{8,9}$ and reduction of the rate of subsequent stroke in cases of symptomatic high-grade internal carotid arterial stenosis treated by carotid endarterectomy. ${ }^{10}$ However, these benefits accrue only with significant short-term risks: a sixfold increased risk of intracranial hemorrhage from $\mathrm{tPA}^{8,9}$ and an increased risk of perioperative stroke and death with carotid endarterectomy that varies as a function of the surgeon. ${ }^{11}$

In the consent discussion, the neurologist must explain the concept of accepting an increased shortterm risk to accrue the long-term benefit of improved outcome. ${ }^{12}$ Many patients are willing to make this trade-off because of their wish to do whatever is necessary to improve their long-term health. However, there are two circumstances in which patients or proxies may choose not to consent: when the patient's life expectancy is too short to accrue the longterm benefit and when the patient's value system ranks short-term health considerations over longterm ones. Because the net benefit of stroke reduction from carotid endarterectomy does not occur until after several months, ${ }^{10}$ it would not be sensible for terminally ill patients with symptomatic carotid stenosis to undergo this procedure. For patients who value reduction of morbidity in the short term over a greater statistical chance for long-term improvement, tPA would not be a sensible treatment. ${ }^{13}$

Balancing long-term benefits against short-term risks is a sophisticated concept that many patients or proxies may not be able to comprehend fully. Although it is difficult and time-consuming, especially in emergency situations, obtaining consent by presenting and discussing this information is essential for the consent to be valid. Because not every patient or proxy is willing to undergo an increase in shortterm risk to accrue a greater chance of a long-term benefit, it is unethical to omit this discussion during the consent process.

Given the urgent nature of treatment with tPA and the lack of capacity of many eligible patients to consent because of aphasia, it may not be possible for clinicians to obtain proxy consent within the time window necessary for safety. Legal doctrines exist that authorize emergency treatment in the absence of consent, such as the emergency treatment doctrine and the doctrine of presumed consent. These doctrines are applicable, however, only when the treatment in question represents the usual standard of emergency care. Whether tPA can be administered without consent in this circumstance thus depends on whether tPA treatment is considered the usual standard of emergency care for ischemic infarction. This determination, in turn, depends on the evolving efficacy and safety data for tPA and the treatment recommendations from expert bodies.

Consent for participation in research. Patients with cerebrovascular diseases or other conditions may be approached to become research subjects. Several ethical issues involved in the protection of patients as research subjects were discussed in a recent AAN position paper. ${ }^{14}$ In addition to requiring that an institutional review board approve both the scientific validity and patient safety aspects of the research protocol, and the adequacy of the patient consent form, the subject's valid consent for participation in research remains one of the greatest protections that researchers can provide to research subjects. Valid consent for participation in research requires the same criteria as valid consent for clinical care: adequate decision-making capacity, adequate information, and lack of coercion. The researcher obtaining patient consent should carefully consider several additional factors.

The standard for adequacy of information to be conveyed for research participation by patients often exceeds that for clinical care. Potential research subjects require a dialogue explaining the purposes of the research and the exact role, benefits, and harms the subject may undergo. Additionally, a written consent form containing all relevant information should be studied and signed by the research subject. Generally, the form stipulates that the research subject has had an opportunity to have all questions answered and is volunteering without coercion. The form identifies the person to contact if the research subject develops any problems or has any subsequent questions. The consent should contain an "escape clause" permitting the subject to discontinue 
participation from the study at any time without penalty.

Investigators should be sensitive to the concept of subtle coercion caused by conflicts of interest. Neurologists who simultaneously provide clinical care and perform research using their patients as subjects may have a conflict of interest that creates unintended pressure on patients to participate. $\mathrm{Pa}$ tients may consent more from a sense of obligation or gratitude to the neurologist than because they affirmatively wish to participate in the study. Neurologists should be aware of such conflicts and try to handle them judiciously and always in their patients' best interests. ${ }^{15,16}$

Proxy consent for cognitively incapacitated patients to serve as research subjects also requires protections greater than those of ordinary proxy consent for clinical care. The American College of Physicians has recommended that proxies should provide consent in such cases only if there is a reasonable probability that the cognitively incapacitated patient may be helped more than harmed by the proposed protocol. ${ }^{17}$ A New York court recently upheld this position. ${ }^{18,19}$

Consent for research in emergency circumstances often cannot be obtained because of the very nature of the emergency condition. In a recent policy, drawing on the doctrine of presumed consent, the United States Food and Drug Administration and the Department of Health and Human Services outlined the criteria for waiving the otherwise ordinary requirement of obtaining valid consent in emergency treatment research protocols on critically ill subjects. ${ }^{20}$

\section{Disclaimer}

This statement is provided as an educational service of the American Academy of Neurology. It is based on an assessment of current scientific and clinical information. It is not intended to include all possible proper methods of care for a particular neurologic problem or all legitimate criteria for choosing to use a specific procedure. Neither is it intended to exclude any reasonable alternative methodologies. The American Academy of Neurology recognizes that specific patient care decisions are the prerogative of the patient and the physician caring for the patient, based on all of the circumstances involved.

\section{Appendix}

American Academy of Neurology Ethics and Humanities Subcommittee members: James L. Bernat, MD (principal author); H. Richard Beresford, MD, JD; Michael P. Earnest, MD; David Goldblatt, MD; Glenn A. Mackin, MD; Michael P. McQuillen, MD; Robert F. Nelson, MD; Lois M. Nora, MD, JD; Russell D. Snyder, Jr., MD; and Robert M. Taylor, MD.

\section{References}

1. American Academy of Neurology Ethics and Humanities Subcommittee. Position statement: Certain aspects of the care and management of profoundly and irreversibly paralyzed patients with retained consciousness and cognition. Neurology 1993;43:222-223.

2. Bernat JL, Cranford RE, Kittredge FI Jr, Rosenberg RN. Competent patients with advanced states of permanent paralysis have the right to forgo life-sustaining therapy. Neurology 1993;43:224-225.

3. American Academy of Neurology Ethics and Humanities Subcommittee. Position of the American Academy of Neurology on certain aspects of the care and management of the persistent vegetative state patient. Neurology 1989;39:125-126.

4. American Academy of Neurology Ethics and Humanities Subcommittee. Ethical issues in the management of the demented patient. Neurology 1996;46:1180-1183.

5. Bernat JL, Goldstein ML, Viste KM, Jr. The neurologist and the dying patient. Neurology 1996;46:598-599.

6. American Academy of Neurology Ethics and Humanities Subcommittee. Palliative care in neurology. Neurology 1996;46: $870-872$.

7. Gert B, Nelson WA, Culver CM. Moral theory and neurology. Neurol Clin 1989;7:681-696.

8. The National Institute of Neurological Disorders and Stroke rt-PA Stroke Study Group. Tissue plasminogen activator for acute ischemic stroke. N Engl J Med 1995;333:1581-1587.

9. Quality Standards Subcommittee of the American Academy of Neurology. Practice advisory: thrombolytic therapy for acute ischemic stroke-summary statement. Neurology 1996;47: 835-839.

10. North American Symptomatic Carotid Endarterectomy Trial Collaborators. Beneficial effect of carotid endarterectomy in symptomatic patients with high-grade carotid stenosis. N Engl J Med 1991;325:445-453.

11. Wennberg DE, Lucas FL, Birkmeyer JD, Bredenberg CE, Fisher ES. Variation in carotid endarterectomy mortality in the Medicare population: trial hospitals, volume, and patient characteristics. JAMA 1998;279:1278-1281.

12. Nadeau SE. Decision analysis and carotid endarterectomy. J Stroke Cerebrovasc Dis 1993;3:244-255.

13. Riggs JE. Tissue-type plasminogen activator should not be used in ischemic stroke. Arch Neurol 1996;53:1306-1308.

14. American Academy of Neurology Ethics and Humanities Subcommittee. Ethical issues in clinical research in neurology: advancing knowledge and protecting human research subjects. Neurology 1998;50:592-595.

15. Bernat JL, Goldstein ML, Ringel SP. Conflicts of interest in neurology. Neurology 1998;50:327-331.

16. Miller FG, Rosenstein DL, DeRenzo EG. Professional integrity in clinical research. JAMA 1998;280:1449-1454.

17. American College of Physicians. Cognitively impaired subjects. Ann Intern Med 1989;111:843-848.

18. TD v New York State Office of Mental Health and Department of Health, $228 \mathrm{AD}$ 2nd 95 (App. Div., First Dept., 5 Dec 1996).

19. Haimowitz S, Delano SJ, Oldham JM. Uninformed decisionmaking: the case of surrogate research consent. Hastings Cent Rep 1997;27(6):9-16.

20. Wichman A, Sandler AL. Research involving critically ill subjects in emergency circumstances: new regulations, new challenges. Neurology 1997;48:1151-1157. 


\section{Neurology}

\section{Consent issues in the management of cerebrovascular diseases: A Position Paper of the American Academy of Neurology Ethics and Humanities Subcommittee}

Neurology 1999;53;9

DOI 10.1212/WNL.53.1.9

\section{This information is current as of July 1,1999}

\section{Updated Information \&} Services

References

Citations

Permissions \& Licensing

Reprints including high resolution figures, can be found at: http://n.neurology.org/content/53/1/9.full

This article cites 17 articles, 9 of which you can access for free at: http://n.neurology.org/content/53/1/9. full\#ref-list-1

This article has been cited by 3 HighWire-hosted articles: http://n.neurology.org/content/53/1/9.full\#\#otherarticles

Information about reproducing this article in parts (figures,tables) or in its entirety can be found online at:

http://www.neurology.org/about/about_the_journal\#permissions

Information about ordering reprints can be found online:

http://n.neurology.org/subscribers/advertise

Neurology ${ }^{\circledR}$ is the official journal of the American Academy of Neurology. Published continuously since 1951, it is now a weekly with 48 issues per year. Copyright . All rights reserved. Print ISSN: 0028-3878. Online ISSN: 1526-632X.

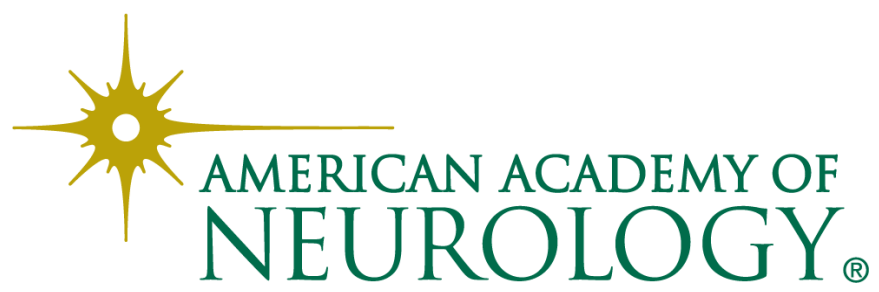

